Yanık Tedavisi Gören Çocukların Annelerinin Uyguladığı İlk Yardım Müdahalesi ve Bilgisi

\title{
First Aid Intervention and Knowledge Applied by Mothers of Children with Burn
}

Hesna Gurler ${ }^{1}$, İknur Yıldız

${ }^{1}$ Sivas Cumhuriyet Üniversitesi, Sağlık Bilimleri Fakültesi, Hemşirelik Bölümü, Cerrahi Hastalıklar Hemşireliği A.D, Sivas

${ }^{2}$ Sivas Cumhuriyet Üniversitesi, Sağlık Bilimleri Fakültesi, Hemşirelik Bölümü, Çocuk Sağlı̆̆ı ve Hastalıkları Hemşireliğii, Sivas

\section{$\ddot{O} Z$}

GIRIŞ: Yanık tedavi merkezlerinde her yıl tedavi edilen yanık vakalarının çoğunluğu çocuk hastalar oluşturmaktadır. Ancak yapılan çalışmalar çocuklara doğru ilk yardım müdahalesinde bulunulmadığını göstermektedir. Araştırma yanık tedavisi gören çocukların annelerinin yanık sonrası uyguladıkları ilk yardım müdahalesi ve bilgisini belirlemek amacı ile tanımlayıcı olarak yapıldı.

GEREÇ ve YÖNTEM: Çalışmaya bir devlet hastanesinin yanık ünitesinde tedavi gören 0-16 yaş arası 60 çocuk ve annesi alındı. Veriler yanık kliniğinde Tanıtıcı Bilgiler ve Yanıkta İlk Yardım Bilgisi Formu kullanılarak yüz yüze görüşme tekniği ile toplandı. Veriler yüzdelik dağılımlar, ortalama ve ki kare testi kullanılarak değerlendirildi.

BULGULAR: Annelerin \%70'inin yanıkta ilkyardım konusunda bilgi almadığı ve bilgi düzeylerinin yeterli olmadığı, yanıkta ilk yardım müdahalesi olarak yanık bölgesine su $(\% 53,3)$, yoğurt, yanık merhemi (\%6.7), buz (\%5.5), zeytinyağı, diş macunu (\%3.3) uyguladığı, \%18.3'ünün hiçbir uygulama yapmadan hastaneye götürdüğü saptandı. Çocukların \%41,7'sinde yanık yarası ile ilişkili problem geliştiği, en sık gelişen problemin geç iyileşme (\%68) olduğu belirlendi. Yanık ile ilişkili problem gelişme oranı ilk yardım müdahalesi olarak yanık bölgesini akan suya tutan ve ilk yardım konusunda bilgisi olan annelerin çocuklarında istatistiksel açıdan önemli düzeyde daha düşüktü.

SONUÇ: Annelerin ilk yardım konusunda bilgi düzeyleri ve doğru ilkyardım müdahalesi uygulama oranlarının yetersiz, yanık yarasına ilk yardım müdahalesi olarak sadece su uygulanmasının yanık yarasının iyileşmesinde önemli etkiye sahip olduğu belirlendi. Çalışmadan elde edilen bu bulgulara göre, aile, okul, hastane ve topluma dayalı yanıkta doğru ve yanlış ilkyardım uygulamalarını içeren farkındalık programları geliştirilmesi önerilmektedir.

Anahtar kelimeler: Anne, çocuk, yanık, ilk yardım, bilgi 


\section{SUMMARY}

INTRODUCTION: Most of burn cases treated at burn treatment centers each year are pediatric patients. However, studies show that children with burns are not treated with correct first aid intervention. The study was carried out as a descriptive study to determine the first aid intervention and knowledge of the mothers of the children who were treated with burns.

MATERIAL and METHOD: Sixty children between the ages of 0-16 who were treated at a state hospital's burn unit and their mothers were included to the study. The data were collected by face-to-face interview technique by using Introductory Information and First Aid Knowledge Form. Data were evaluated using percentage distributions, means and chi-square test.

RESULTS: It was found that $70 \%$ of mothers did not receive information about first aid in burns and that their knowledge levels were low, Overall, mothers treated burns with water (53.3\%), yoghurt and burn oinment (6.7\%) ice (5.5\%), olive oil (3.3\%) and toothpaste, $18.3 \%$ took children to hospital without any application. It was determined that the problem associated with the burn wound occurred in $41.7 \%$ of the children and the most common problem was delayed wound healing. The rates of problem development were statistically significantly lower in the children of mother who treated burns with running water and who have knowledge about first aid for burns.

CONCLUSION: It was determined that mothers' knowledge about first aid in burn and rate of correct and effective first aid intervention were low, only water application as a first aid intervention to the burn wound had a significant effect on the healing of the burn wound. According to these findings, it is recommended that awareness programmes that include right and wrong first aid applications in family, school, hospital and community settings should be developed for first aid interventions.

Keywords: Mother, child, burn, first aid, knowledge 


\section{Giriş}

Yanıklar ciddi fiziksel, fonksiyonel ve psikososyal sonuçları olan evrensel bir toplum sağlığ problemidir (1-5). Dünya Sağl1k Örgütü 2016 raporuna göre çoğunluğu düşük ve orta gelirli ülkelerde olmak üzere dünya genelinde her yıl 180.000 kişi yanık nedeniyle hayatını kaybetmektedir (6). Ülkemizdeki yanık tedavi merkezlerinde her yıl tedavi edilen yanık vakalarının çoğunluğu çocuk hastalardır $(7,8)$. Yanıklar 0-19 yaş çocuklarda da ciddi oranlarda ölümle sonuçlanan ve ölüm nedenleri arasında 13. sırada yer alan yaralanmalardır $(5,9)$.

Yanık sonrası ilk saat "altın saat" olarak ifade edilmektedir (10). Bu sürede yapılan doğru ve etkin ilk yardım müdahalesi yanık alanında ağrıyı, doku hasarı boyutunu, hastanede kalış süresini ve ölüm oranlarını azaltmakla birlikte epitel hücrelerin hızla çoğalmasını sağlayarak yanık iyileşmesini de hızlandırmaktadır $(3,10,11)$. Ancak yapılan çalışmalarda yanmış çocuklara hastane öncesi doğru ve yeterli ilk yardımda bulunulmadığı, yanık yarasında ağrıyı azaltmak ve iyileştirmek amacıyla su kullanımının yetersiz olduğu, motor yağı, salça, tereyağı, dilimlenmiş patates, diş macunu gibi geleneksel tedavi yöntemlerinin ise yaygın olarak kullanıldığ bildirilmektedir (3,4,7,8,12-15). Literatürden elde edilen bu bulgular annelerin yanıkta ilkyardım bilgisinin yetersiz olduğunu göstermektedir. Yanıkta yapılan doğru ve etkin ilk müdahale yanık şiddetinin ve greft ihtiyacının azaltılmasını sağlayarak yanık iyileşmesini hızlandırmaktadır $(3,12,14)$. Bu nedenle evde ilk müdahaleyi yapan kişinin çoğunlukla anne olması nedeniyle annenin yanıkta doğru ilk yardım uygulaması yanık iyileşme sürecinde oldukça önemli etkiye sahiptir $(13,16)$. Ülkemizde çocuklarda yanıkta ilk yardım uygulamalarını araştıran çeşitli çalışmalar vardır, (4,5,7,8,15), ancak annelerde yanıkta ilkyardım uygulamaları ile birlikte ilk yardım bilgisini değerlendiren çalışmaya rastlanmamıştır. $\mathrm{Bu}$ doğrultuda bu çalışma yanık tedavisi gören çocukların annelerinin yanıkta uyguladıkları ilk yardım müdahalesi ve ilkyardım bilgisini belirlemek amacıyla tanımlayıcı olarak yapıldı.

\section{Gereç ve Yöntem}

Çalışma bir devlet hastanesinin Yanık Ünitesinde tanımlayıcı olarak gerçekleştirildi. Çalışmanın evrenini 01 Şubat 2018-31 Aralık 2018 tarihleri arasında yanık nedeniyle tedavi gören 65 çocuk ve annesi oluşturdu. Çalışmanın örneklemini ise Türkçe konuşabilen ve çalışmaya katılmayı kabul eden 60 çocuk annesi oluşturdu. 5 çocuk annesi yabancı uyruklu olması nedeniyle iletişim kurulamadığı için çalışmaya dahil edilmedi. Veriler hastane odasında yüz yüze görüşme tekniği ile toplandı. Anneler yanıkta ilk yardım konusundaki bilgi düzeyleri değerlendirildikten sonra, yanıkta ilk yardım konusunda bilgilendirildi.

Verilerin toplanmasında araştırmacılar tarafından literatüre dayalı olarak geliştirilen Tanıtıcı Bilgiler Formu ve Yanıkta İlk Yardım Bilgisi Formu kullanıldı $(3,7,14)$. Tanıtıcı Bilgiler Formu çocuğun yaşı; annenin eğitim durumu, yaşı ve mesleği; babanın eğitim durumu, yaşı ve mesleği; sürekli yaşanan yer, kalınan evin ısınma durumu, çocuğun daha önce yanma durumu, yanık derecesi, hastanede kalış süresi, iyileşme 
sürecinde yanık yarasında herhangi bir problem gelişme durumu, geliştiği ise gelişen problem; yanmanın gerçekleştiği yer, yanma nedeni; yanığa yapılan ilk yardım müdahalesi; daha önce yanıkta ilkyardım konusunda herhangi bir bilgi alma durumu, ilk yardım bilgisini aldığı kişi olmak üzere toplam 19 sorudan oluşmaktadır. Yanıkta İlk Yardım Bilgi Formu doğru yanlış bilmiyorum şeklinde ifade edilen yanıkta uygulanan ilkyardım bilgi ifadelerini içeren 15 maddeden oluşmaktadır. Çalışmamızdan elde edilen veriler SPSS 22.00 programında değerlendirildi ve verilerin değerlendirilmesinde yüzdelik dağılımlar, ortalama ve ki kare testi kullanıldı. Araştırmaya başlamadan önce çalışmanın yürütüldüğü ilin Klinik Olmayan Araştırmalar Etik Kurulu'ndan etik onay alındı (Etik onay no: 2017-10/17). Çalışmanın yürütüleceği kurumdan izin alındıktan sonra araştırmaya katılan bireylerden yazılı ve sözel izin alındı. Anneler araştırma hakkında detaylı olarak bilgilendirildi. Anketler annelere çocukların tedavi ve beslenme saatleri dışındaki saatlerde uygulandı. Anket formunun doldurulması ve form doldurulduktan sonra yanıkta ilk yardım konusunda bilgilendirme yaklaşık 25 dakika sürdü.

\section{Bulgular}

Yanık tedavisi gören çocukların \%75'i 0-3 yaş arasındadır. Çalışmaya katılan annelerin yaş ortalaması $29.55 \pm 6.06, \% 70$ 'i ilköğretim mezunu ve \%48'i ev hanımıdır. Ailelerin \%50'si il merkezinde, \%45'i sobalı bir evde yaşamaktadır (Tablo 1).

Tablo 1. Çalışmaya Katılan Çocuk ve Annelerin Sosyodemografik Özellikleri

\begin{tabular}{|c|c|c|}
\hline Tanıtıcı Özellikler & $N(n=60)$ & $\%$ \\
\hline \multicolumn{3}{|l|}{ Çocuğun yaş grubu } \\
\hline $0-3$ yaş & 45 & 75.0 \\
\hline 3-6 yaş & 8 & 13.3 \\
\hline $6-12$ yaş & 6 & 10.0 \\
\hline $12-18$ yaş & 1 & 1.7 \\
\hline \multicolumn{3}{|l|}{ Anne eğitim düzeyi } \\
\hline İlköğretim & 42 & 70.0 \\
\hline Lise & 8 & 13.3 \\
\hline Üniversite & 10 & 16.7 \\
\hline \multicolumn{3}{|c|}{ Anne Yaşı: $\mathrm{X} \pm \mathrm{SD}=29.55 \pm 6.06$} \\
\hline \multicolumn{3}{|c|}{ Anne çalışma durumu } \\
\hline Çalışıyor & 12 & 20.0 \\
\hline Çalışmıyor & 48 & 80.0 \\
\hline \multicolumn{3}{|l|}{ Yaşanılan yer } \\
\hline İl & 30 & 50.0 \\
\hline İlçe & 9 & 15.0 \\
\hline Köy & 21 & 35.0 \\
\hline \multicolumn{3}{|c|}{ Yaşanılan evin ısınma durumu } \\
\hline Soba & 27 & 45.0 \\
\hline Kalorifer & 33 & 55.0 \\
\hline
\end{tabular}


Yanık ve ilk yardım müdahalesine ilişkin özellikler Tablo 2'de verilmiştir.

Tablo 2. Çocukların Yanık Özellikleri ve Annelerin Uyguladıkları İlk Yardım Müdahaleleri

\begin{tabular}{|c|c|c|}
\hline Yanık Özellikleri & $\mathbf{N}(\mathbf{n}=60)$ & $\%$ \\
\hline \multicolumn{3}{|c|}{ Çocuğun daha önce yanma durumu } \\
\hline Evet & 6 & 10.0 \\
\hline Hayır & 54 & 90.0 \\
\hline \multicolumn{3}{|c|}{ Hastanede kalış süresi: $\quad \mathbf{X} \pm \mathbf{S D} \quad=6.00 \pm 4.18$ gün } \\
\hline \multicolumn{3}{|c|}{ İyileşme sürecinde yanık bölgesinde problem gelişme durumu } \\
\hline Evet & 25 & 41.7 \\
\hline Hayır & 35 & 58.3 \\
\hline \multicolumn{3}{|l|}{ Gelişen problem $(n=25)$} \\
\hline Geç iyileşme & 17 & 68.0 \\
\hline Kanama & 4 & 16.0 \\
\hline Enfeksiyon & 2 & 8.0 \\
\hline Ödem & 2 & 8.0 \\
\hline \multicolumn{3}{|l|}{ Yanmanın gerçekleştiği yer } \\
\hline Ev içi & 53 & 88.3 \\
\hline Ev diş1 & 7 & 11.7 \\
\hline \multicolumn{3}{|c|}{ Yanığa yapılan ilk yardım müdahalesi* } \\
\hline Su uygulama & 32 & 53.3 \\
\hline $\begin{array}{l}\text { Su uygulamas1 ve diğer } \\
\text { yöntemler }\end{array}$ & 9 & 15.0 \\
\hline Diğer yöntemler & 19 & 31.7 \\
\hline $\begin{array}{l}\text { Hiçbir uygulama yapmadan } \\
\text { hastaneye götürme }\end{array}$ & 14 & 23.3 \\
\hline Yoğurt & 4 & 6.7 \\
\hline Yanık merhemi & 4 & 6.7 \\
\hline Buz uygulama & 3 & 5.0 \\
\hline Zeytinyağ1 & 2 & 3.3 \\
\hline Diş macunu & 2 & 3.3 \\
\hline Salça & 1 & 1.7 \\
\hline Elma kabuğu & 1 & 1.7 \\
\hline Çiğ yumurta akı & 1 & 1.7 \\
\hline Soğan & 1 & 1.7 \\
\hline
\end{tabular}


Tablo 2. Çocukların Yanık Özellikleri ve Annelerin Uyguladıkları İlk Yardım Müdahaleleri (Devamı)

\begin{tabular}{|l|c|c|}
\hline Yanma nedeni & \multicolumn{2}{|c|}{} \\
\hline Sıcak su dökülmesi & 71 & 85.0 \\
\hline Sıcak objeye dokunma & 2 & 11.7 \\
\hline Alev yanığı & \multicolumn{2}{|c|}{} \\
\hline Illk yardım konusunda bilgi alma durumu & 3.3 \\
\hline Evet & 18 & 30.0 \\
\hline Hayır & 42 & 70.0 \\
\hline Illk yardım bilgisi alınan yer (n=18) & 2 & 11.1 \\
\hline TV & 9 & 50.0 \\
\hline Örgün eğitim & 4 & 22.2 \\
\hline Sağlı personeli & 2 & 11.1 \\
\hline Akraba & 1 & 5.6 \\
\hline İnternet & \multicolumn{2}{|c|}{} \\
\hline
\end{tabular}

* Birden fazla cevap verilmişstir.

Çocukların \%10'unun daha önce de yanık tedavisi gördüğü, tümünün 2. derece yanık ile ortalama $6.00 \pm 4.18$ gün hastanede yattığı, yanıkların \%88.3'ünün ev ortamında sıcak su dökülmesi (\%85) nedeni ile gerçekleştiği saptandı. İyileşme sürecinde çocukların \%41.7'sinde yanık yarası ile ilişkili problem geliştiği ve gelişen problemin \%68 oranında geç iyileşme olduğu belirlendi Annelerin yanığa yaptıkları ilk yardım müdahalesi değerlendirildiğinde \%53.3'ünün çocuğun yanan bölgesini akan suya tuttuğu, \%23.3'ünün hiçbir uygulama yapmadan hastaneye götürdüğü, \%6.7'sinin yanık bölgesine yoğurt ve yanık merhemi, \%5.5' inin buz, \%3.3'ünün zeytinyağı ve diş macunu, \%1.7'sinin salça, elma kabuğu, çiğ yumurta akı ve soğan uyguladığı belirlendi. Annelerin \%70'inin yanıkta ilkyardım konusunda bilgi almadığı, bilgi alanlarda temel bilgi kaynağının \%50 oranı ile örgün eğitim olduğu belirlendi.

Çalışmaya katılan annelerin \%83'ünün yanma sırasında çocuğun derisine yapışmış giysilerin çıkarılmamasını, \%75'inin yanık yarasına salça, \%56,7'sinin yoğurt sürmenin, \%43.3’ünün direkt buz uygulamanın ağrıyı azaltmadığını ifade ettiği bulundu. Annelerin \%63,3'ü yanan yere yumurta, salça, diş macunu gibi şeyler sürmenin yaranın mikrop kapma olasıllı̆ını \% 58,3 'ünün alerji riskini artırdığını bildiği belirlendi. \%66.7'si yanıkta yapılması gereken en doğru müdahalenin 20-30 dakika akan suya tutmak olduğunu belirtmiştir. Annelerin \%55'i yanık alanına nemli örtü örtülmesinin, \%50'si bandaj uygulanarak hava ile temasının önlenmesinin, \%60’1 yanık bölgesini kalp hizasına yükseltilmesinin ve \%55'i yanık alanında oluşan içi su dolu kabarcıklanın patlatılmamasının doğru olduğunu ifade etmiştir. Alev kaynaklı yanıklarda alevin sönmesi için \%51.7'si bireyin koşmaması, \%60’ı üzerinin bir kumaşla örtülerek hafifçe çevrilmesi gerektiğini belirtmiştir (tablo 3). 
Tablo 3. Annelerin Yanıkta İlk Yardım Bilgi Düzeyleri

\begin{tabular}{|c|c|c|c|c|c|c|}
\hline \multirow[t]{2}{*}{ Yanıkta ilk yardım bilgi ifadeleri } & \multicolumn{2}{|c|}{ Doğru } & \multicolumn{2}{|c|}{ Yanlış } & \multicolumn{2}{|c|}{ Bilmiyorum } \\
\hline & $\mathbf{N}$ & $\%$ & $\mathbf{N}$ & $\%$ & $\mathbf{N}$ & $\%$ \\
\hline $\begin{array}{l}\text { 1. Yanma sırasında çocuğun derisine yapışmış } \\
\text { giysiler çıkarmak için zorlanmamalı ve } \\
\text { çekilmemelidir. }\end{array}$ & 50 & 83.3 & 4 & 6.7 & 6 & 10.0 \\
\hline $\begin{array}{l}\text { 2.Yanık yarasına diş macunu sürmek iyileşmeyi } \\
\text { hızlandırır }\end{array}$ & 3 & 5.0 & 42 & 70.0 & 15 & 25.0 \\
\hline 3. Yanık yarasına salça sürmek ağrıyı azaltır & 1 & 1.7 & 45 & 75.0 & 14 & 23.3 \\
\hline 4.Yanık yarasına yoğurt sürmek ağrıyı azaltır & 10 & 16.7 & 34 & 56.7 & 16 & 26.7 \\
\hline $\begin{array}{l}\text { 5.Yanıkta yapılması gereken en doğru ilk yardım } \\
\text { uygulaması yanan yerin 20-30 dakika akan suya } \\
\text { tutulmasıdır. }\end{array}$ & 40 & 66.7 & 7 & 11.7 & 13 & 21.7 \\
\hline 6. Yanan yere direkt buz konularak ağrı azaltılır & 12 & 20.0 & 26 & 43.3 & 22 & 36.7 \\
\hline 7.Yanan yere yumurta sürmek yanık izini azaltır & 7 & 11.7 & 26 & 43.3 & 27 & 45.0 \\
\hline $\begin{array}{l}\text { 8. Yanan yere yumurta, salça, diş macunu gibi şeyler } \\
\text { sürmek yaranın mikrop kapma olasılığını artırır. }\end{array}$ & 38 & 63.3 & 4 & 6.7 & 18 & 30.0 \\
\hline $\begin{array}{l}\text { 9. Yanan yere yumurta, yoğurt gibi şeyler sürmek } \\
\text { alerji olasıllığını artırır. }\end{array}$ & 35 & 58.3 & 6 & 10.0 & 19 & 31.7 \\
\hline $\begin{array}{l}\text { 10. Yanık alanı temiz yapışkan olmayan nemli bir } \\
\text { örtü ile örtülmelidir }\end{array}$ & 33 & 55.0 & 6 & 10.0 & 21 & 35.0 \\
\hline $\begin{array}{l}\text { 11.Yanık alanına bandaj uygulanarak hava ile teması } \\
\text { önlenmelidir. }\end{array}$ & 30 & 50.0 & 15 & 25.0 & 15 & 25.0 \\
\hline $\begin{array}{l}\text { 12. Yanık alanında oluşan içi su dolu kabarcıklar } \\
\text { delinmemeli/patlatılmamalıdır. }\end{array}$ & 33 & 55.0 & 16 & 26.7 & 11 & 18.3 \\
\hline $\begin{array}{l}\text { 13. Yanık el, kol, ayak veya bacaklarda ise bu } \\
\text { kısımlar alta destek konularak kalp hizasına } \\
\text { yükseltilmelidir. }\end{array}$ & 36 & 60.0 & 7 & 11.7 & 17 & 28.3 \\
\hline $\begin{array}{l}\text { 14. Alev kaynaklı yanıklarda bireye koşması } \\
\text { söylenerek alevin sönmesi sağlanır. }\end{array}$ & 18 & 30.0 & 31 & 51.7 & 11 & 18.3 \\
\hline $\begin{array}{l}\text { 15. Alev kaynaklı yanıklarda bireyin üzeri battaniye } \\
\text { veya kalın bir kumaşla örtülerek hafifçe çevrilmelidir. }\end{array}$ & 36 & 60.0 & 8 & 13.3 & 16 & 26.7 \\
\hline
\end{tabular}

Annelerin yanıkta ilk yardım müdahalesi ve bilgisine göre yanıkla ilişkili problem gelişme durumu değerlendirildiğinde (Tablo 4), problem gelişme oranlarının yanık durumunda ilk yardım müdahalesi olarak hiçbir şey yapılmadan hastaneye götürülen ya da zararlı yöntemlerin uygulandığı (\%77.8) $\left(X^{2}=14.588, \mathrm{p}<0.001\right)$ ve annesi yanıkta ilk yardım konusunda bilgi sahibi olmayan çocuklarda $(\% 50)$ istatistiksel olarak önemli düzeyde daha yüksek $\left(X^{2}=4.00, \mathrm{p}<0.05\right)$ olduğu saptandı. 
Tablo 4. Annelerin Yanıkta Uyguladığı İlk Yardım Müdahalesi ve Bilgisine Göre Yanıkla İlişkili Problem Gelişme Durumu

\begin{tabular}{|c|c|c|c|c|c|}
\hline & \multicolumn{4}{|c|}{ Problem gelişme durumu } & \multirow{2}{*}{$\begin{array}{l}\text { İstatistiksel } \\
\text { analiz }\end{array}$} \\
\hline & \multicolumn{2}{|c|}{ Evet } & \multicolumn{2}{|c|}{ Hayır } & \\
\hline Yanıkta ilk yardım müdahalesi & $\mathrm{N}$ & $\%$ & $\mathrm{~N}$ & $\%$ & \\
\hline Yalnızca su uygulama & 7 & 22.6 & 24 & 77.4 & \multirow{3}{*}{$\begin{array}{c}X^{2}=14.588 \\
p<0.001\end{array}$} \\
\hline Su ve diğer yöntemler & 3 & 33.3 & 6 & 66.7 & \\
\hline Diğer yöntemler* & 14 & 77.8 & 4 & 22.2 & \\
\hline \multicolumn{6}{|l|}{$\begin{array}{l}\text { Yanıkta ilk yardım konusunda } \\
\text { bilgi sahibi olma durumu }\end{array}$} \\
\hline Evet & 4 & 22.2 & 14 & 77.8 & $X^{2}=4.00$ \\
\hline Hayır & 21 & 50.0 & 21 & 50.0 & $\mathrm{p}<0.05$ \\
\hline
\end{tabular}

*Hiçbir uygulama yapmama, buz uygulama, yoğurt, diş macunu, salça, elma kabuğu, çiğ yumurta ak1

\section{Tartısma}

Yanıkta doğru ve hemen yapılan ilkyardım müdahalesi ağrıyı ve doku hasarı boyutunu önemli ölçüde azaltarak yanık iyileşmesini hızlandırmakta ve hayatta kalma oranını artırmaktadır $(3,12,14)$. Yanıkta ilk yardım uygulamalarını araştıran güncel kanıtlar yanık yarasına su dışında hiçbir şeyin uygulanmaması gerektiğini, yanık bölgesinin yaralanmadan sonraki ilk 3 saat içinde 20 dakika $2-15{ }^{\circ} \mathrm{C}$ akan suda tutulmasının yanıkta en uygun ilkyardım müdahalesi olduğunu bildirmektedir $(5,6,12,14,16,17)$. Bu tedavi mast hücreleri ve histamin salınımını stabilize ederek yanık alanında ödem ve ağrıyı azaltmakla birlikte (4), epitel hücrelerinin hızlı çoğalmasını sağlayarak yara iyileşmesini de hızlandırmakta ve skar doku oluşumunu azaltmaktadır (16-18). Ancak dünya genelinde çocuk ve yetişkinlerle yapılan çalışmalarda yanıkta ilkyardım müdahalesi olarak su kullanımının istendik düzeyde olmadığı $(2-4,7,11,12,15,19)$, su uygulamasının ne kadar süre yapılacağı konusunda bilgilerinin olmadığ $(14,20)$ ve suyun zarar verebileceği inancına sahip oldukları $(3,10)$ bildirilmektedir. Outwater ve ark.nın (2018) Tanzanya'da yanık durumunda hastane öncesi uygulanan tedavi yöntemlerini araştırdıkları bir metanaliz çalışmasında ilk yardım müdahalesi olarak su kullanım oranının \%14.3 (21); Suudi Arabistan'da yapılan bir çalışmada \%54.6 (12), Hindistan'da yapılan bir çalışmada ise \%20.3 olduğu belirlenmiştir (2). Çalışmamızda da yanık yarasına su uygulayan anne oranı \%53.3 olarak belirlenmiş olup bu oranın yeterli olmadığı görülmektedir. Çalışmada ayrıca yalnızca su uygulanan çocuklarda yanık ile ilişkili problem gelişme oranının diğer yöntemlerin uygulandığı çocuklardan önemli ölçüde daha düşük olduğu saptandı. Fadeyibi ve ark. (2015)'nın 
çocuk ve yetişkinlerde yanıkta ilk yardım uygulamalarını değerlendirdiği bir çalışmada da yanığa su uygulaması yapan bireylerde üçüncü derece yanık, yanıkla ilişkili komplikasyon oranı ve greft gereksiniminin su uygulamayanlardan daha düşük olduğu belirlenmiştir (19). Harish ve ark. nın (2019) yanık deneyimi olan 4918 bireyle (22) ve Wood ve ark. nın (2016) 2320 bireyle yaptığı kohort çalışmalarında da (18) ilk yardım müdahalesi olarak 20 dakikalık su uygulamasının greft ve yoğun bakım gereksinimi, yanık derinliği, reepitalizasyon zamanı ve ölüm oranını önemli ölçüde azalttığı belirlenmiştir. Çalışmamız ve diğer çalışmadan elde edilen bu bulgular literatürü destekler nitelikte akan su uygulamasının yanık yarasının iyileşmesi üzerindeki olumlu etkisini göstermektedir.

Yanıkta ilk yardım konusunda ebeveynlerin bilgisi yanık sonuçlarını önemli ölçüde etkilemesi ve ağrıyı azaltması açısından oldukça önemlidir (14). Ancak yanıkta ilk yardım konusunda annelerin uygulamalarını değerlendiren çalışmalarda annelerin \%57-85'inin $(7,12,14)$ yanıkta ilk yardım konusunda bilgi almadığı bildirilmektedir. Bizim çalışmamızda literatüre paralel şekilde annelerin \%70'inin yanıkta ilkyardım konusunda bilgi almadığ1, \%34'ünün yanan bölgeyi akan suda tutmanın yanıkta en uygun ilkyardım müdahalesi olduğunu, \%30'unun diş macunu, \%25'inin salça, \%56.7'sinin buz uygulamasının yanıkta ağrıyı azaltmak amacı ile ilk yardım uygulaması olarak kullanılmaması gerektiğini, \%36.7'sının uygulanan bu yöntemlerin enfeksiyon riskini, \%37.7'sinin ise alerji riskini artırdığını bilmediği saptandı. Annelerin yanıkta ilkyardım konusunda yeterli bilgiye sahip olmaması zararlı olabilecek uygulamaların yapılması ile sonuçlanmaktadır $(13,22)$. Çalışmamızda da bu bilgiyi destekler nitelikte annelerin \%31.7'sinin yanıkta ilk yardım müdahalesi olarak çocuklarına ya hiç bir şey uygulama yapmadan hastaneye götürdügü ya da yanık yarası için zararlı olabilecek yoğurt, buz, zeytinyağı, diş macunu, salça, elma kabuğu, çiğ yumurta akı, soğan ve yanık merhemi kullandıkları belirlendi. Çalışmamızdan elde edilen bu bulgular annelerin yanıkta ilkyardım uygulamaları konusunda yeterli bilgiye sahip olmadıklarını ve bu konuda bilgilendirilme gereksinimlerinin olduğunu göstermektedir. Yanıkta bakım vericiler ve toplumun ilk yardım uygulamalarını değerlendiren benzer çalışmalarda da bireylerin \%17.5-46'sının yanık sonrası ilk yardım müdahalesi olarak hiçbir şey yapmadıkları $(8,11,19,21)$, ağrıyı azaltmak ve iyileştirmek amacıyla etkin olmayan geleneksel tedavi yöntemlerinden çiğ yumurta $(4,11,12,14,19)$, buz $(4,7,14)$, yoğurt $(4,7,15)$, salça $(4,14)$, bal $(2,8,14,21)$, tereyă̆ı/margarin/zeytinyağı $(8,11,15)$; dilimlenmiş patates $(3,14,15)$, diş macunu $(2-4,8,14,15)$, idrar ve ezilmiş hamam böceği (17) kullandıkları bildirilmektedir. Yanık yarasına uygulanan bu tür yöntemlerin yanık alanında hava ile teması engelleyerek ağrıyı azaltıcı etkisi vardır, ancak bu yöntemler yanık alanında bakteri proliferasyonunu artırarak enfeksiyona ve alerjik reaksiyonlara yol açabilir $(2,3,13,17)$. Ayrıca yanık yarasına direkt buz uygulaması da yanık bölgesinde vazokonstrüksiyona yol açarak yanık şiddetini artırır, hipotermi ve şoka neden olur $(5,12,16)$. Chirongoma ve ark. nın (2017) ebeveynlerde yanıkta ilk yardım uygulama ve inançlarını değerlendirdiği bir çalışmada da yanık yarasına ilk yardım müdahalesi olarak yumurta ve margarin gibi zararlı maddelerin kullanıldığı çocuklarda yanık alanında enfeksiyon görülme oranının daha 
yüksek olduğu belirlenmiştir (17). Çalışmamızda da yanıkta ilk yardım müdahalesi olarak yoğurt, buz, zeytinyağı, diş macunu, salça, elma kabuğu, çiğ yumurta akı, soğan ve yanık merhemi uygulanan çocuklarda yanık yarası ile ilişkili problem gelişme oranı \%77.8 olarak belirlenmiş olup, bu bulgu zararlı maddelerin yanık için olumsuz etkilere sahip olduğu kanıtını desteklemektedir. Bu nedenle ilk yardım uygulamalarında ne yapılması gerektiğinin bilinmesi kadar nelerin yapılmaması gerektiğinin de bilinmesi yaşamsal önem taşımaktadır $(3,8)$. Yanık yarasına uygulanan ilk yardım müdahalesi doğru ve etkin olduğunda morbidite ve mortaliteyi azaltma etkisi dikkate alındığında, annelerin yanıkta ilkyardım konusunda uygulanması ve uygulanmaması gereken yöntemler konusunda bilgilerinin artırılmasının önemli olduğu düşünülmektedir.

Sınırlılıklar: Çalışmamızda örneklem sayısının az olması ve annelerin su uygulamasını ne kadar süre yaptığının değerlendirilmemesi çalışmanın sınılılıklarıdır. Bu nedenle daha fazla sayıda örneklem grubunun dahil edildiği ve uygulanan ilk yardım yöntemleri ve uygulama sürelerini değerlendiren başka çalışmaların planlanması önerilmektedir.

Sonuç: Çalışmamızda annelerin yanıkta ilk yardım konusunda bilgi ve uygulamalarının istendik düzeyde olmadığı, yanıkta ilk yardım müdahalesi olarak su kullanımının yanık yarasında problem gelişme oranını azalttığı, zararlı uygulamaların ise artırdığı belirlendi. Çalışmamızdan elde edilen bu bulgular doğrultusunda pediatri ve yanık hemşirelerinin, yanıkta kullanılabilecek güncel, doğru ve etkin ilk yardım yöntemleri ve yapılma süreleri, toplumda sık uygulanan diş macunu, salça, yağ gibi geleneksel yöntemlerin zararları konusunda eğitsel programlar geliştirerek bireylerin farkındalığını artırmaları önerilmektedir.

\section{Kaynaklar}

1. Wang $\mathrm{T}$, Nie $\mathrm{C}$, Zhang $\mathrm{H}$, Zeng $\mathrm{X}$, Yu H, Wei Z, et al. Epidemiological characteristics and factors affecting length of hospital stay for children and adults with burns in Zunyi, China: A retrospective study. Peer J 2018;3(6):1-13.

2. Mishra SK, Mahmood S, Baig MA. Burn first aid knowledge and its determinants among general population of Rawalpindi. Eur J Trauma Emerg Surg 2018;22:1-8.

3. Bazargani HS, Fouladi N, Alimohammadi H, Sadeghieh A, Agamohammadi M, Mohamadi R. Prehospital treatment of burns: A qualitative study of experiences, perceptions and reactions of victims. Burns 2013;39(5):860-5.

4. Karaöz B. First-aid home treatment of burns among children and some implications at Milas, Turkey. J Emergency Nurs 2010;36(2):111-4.

5. Kılıç M, Polat S, Çimen S. Çocuklarda Sıvı Elektrolit Dengesi ve Bozuklukları, 2013. Conk Z, Başbakkal Z, Balyılmaz H, Bolışık B (Ed), Pediatri Hemşireliği. 1. Baskı, Ankara, Akademisyen Tıp Kitabevi, 2013: 208-14.

6. World Health Organization, Media centre, fact sheet, burns, https://www.who.int/news-room/factsheets/detail/burns, Erişim tarihi 27.05.2019 
7. Battaloğlu İnanç B, Say Şahin D, Demir C. Mardin il merkezinde 1-6 yaş grubu çocuğu olan annelerin yanıklarda ilk uygulamalarının incelenmesi. Journal of Clinical and Analytical Medicine 2013;4(3):175-8.

8. Çarman KB, Palancı Y, Kılıç K. Anneler yanan çocuklarını tedavi etmek için neler yapıyorlar?. Türkiye Klinikleri J Pediatr 2008;17:169-74.

9. Santomé LM, Leal SMC, Mancia JR, Gomes AMF.Children hospitalized due to maltreatment in the ICU of a Public Health Service. Rev Bras Enferm 2018;71(3):1420-7.

10. Biswas A, Abdullah ASM, Dalal K, Deave T, Rahman F, Mashreky SR. Exploring perceptions of common practices immediately following burn injuries in rural communities of Bangladesh. BMC Health Serv Res 2018;18(1):467.

11. Chirongoma F, Chengetanai S, Tadyanemhandu C. First aid practices, beliefs, and sources of information among caregivers regarding paediatric burn injuries in Harare, Zimbabwe: A crosssectional study. Malawi Med J 2017;29(2):151-4.

12. AlQahtani FA, Alanazi MA, Alanazi MK, Alshalhoub KS, Alfarhood AA, Ahmed SM. Knowledge and practices related to burn first aid among Majmaah community, Saudi Arabia. J Family Med Prim Care 2019;8(2):594-8.

13. Bennett CV, Maguire S, Nuttall D, Lindberg DM, Moulton S, Bajaj L, et al. First aid for children's burns in the US and UK: An urgent call to establish and promote international standards. Burns 2019;45(2):440-9.

14. Alomar M, Rouqi FA, Eldali A, Konowledge, attitude and belief regarding burn first aid among caregivers attending pediatric emergency medicine departments, Burns 2016;42:938-43.

15. Kavurmacı M, Küçükoğlu S. Determination of the pre-hospital practices performed for children with burn injuries, Journal of Clinical and Analaytical Medicine 2015; 6:806-10.

16. Davies M, Maguire S, Okolie W, Watkins W, Kemp AM. How much do parents know about first aid for burns?, Burns 2013;39:1083-90.

17. Varley A, Sarginson J, Young A. Evidence-based first aid advice for paediatric burns in the United Kingdom. Burns 2016;42(3):571-7.

18. Wood FM, Phillips M, Jovic T, Cassidy JT, Cameron P, Edgar DW. Steering water first aid Is beneficial in humans post-burn: Evidence from a bi-national cohort study. Committee of the Burn Registry of Australia and New Zealand (BRANZ). PLoS One 2016;25(11):1-13.

19. Fadeyibi IO, Ibrahim NA, Mustafa IA, Ugburo AO, Adejumo AO, Buari A. Practice of first aid in burn related injuries in a developing country. Burns 2015;41(6):1322-32.

20. Burgess JD, Watt KA, Kimble RM, Cameron CM. Knowledge of childhood burn risks and burn first aid: Cool Runnings. Inj Prev 2018;1-6.

21. Outwater AH, Thobias A, Shirima PM, Nyamle N, Mtavangu G, Ismail M, et al. Prehospital treatment of burns in Tanzania: a mini-meta-analysis. Int J Burns Trauma 2018; 20;8(3):68-76.

22. Harish V, Tiwari N, Fisher OM, Li Z, Maitz PKM. First aid improves clinical outcomes in burn injuries: Evidence from a cohort study of 4918 patients. Burns 2019;45(2):433-9. 